\title{
Cardiovascular and subjective strain during upper limb endurance tests
}

Turpin-Legendre E., Meyer J.P.

INRS, Working Life Dpt, Work Physiology lab.

Vandoeuvre, France

Emmanuelle.turpin-legendre@inrs.fr

\section{Introduction}

Moderate muscular contractions can induce significant cardiovascular strains [1]. Endurance tests of static exertion of the upper limb can be of high interest to assess functional capacities and musculoskeletal disorders [2]. The objective of the study is to evaluate the cardiovascular and subjective strains of different endurance tests to check and prevent the risks of these tests for a systematic use in studies of musculoskeletal disorders in a working population.

\section{Method}

Thirty active young subjects (15 women, 15 men) volunteered to participate in a laboratory study on endurance tests to exhaustion of different upper limb segments. Seven endurance tests to exhaustion were considered: pinch (1), grip (2), flexion (3) and extension (4) of the forearm and adduction (5), flexion (6) and extension (7) of the shoulder. Subjects were sitting. Tests 1 to 4 were achieved with the arm against the thorax, forearm flexed at 90 $\circ$ and hand in prono-supination. Test 5 was done with arm in adduction at $90^{\circ}$ in the frontal plane and test 6 and 7 were done with the arm flexed at $90^{\circ}$ in the sagital plane. All over the tests the subjects have to maintain a constant strength of $30 \%$ of MVC of the corresponding test against a static strength sensor. Strength was continually recorded on a computer and displayed in front of the subject. Exhaustion was defined as the inability of the subject to maintain the required strength displayed in front of him. Throughout the tests heart rate (HR) was recorded continuously (Polar NV), subjective strain estimation (Borg CR-10 scale) was answered each minute and blood pressure (BP) was recorded on the opposite resting upper limb each one and a half minute by an automated sphygmomanometer.

\section{Results}

Mean endurance time was 3.3 minutes for tests 2, 5 and 6, 4.2 (test 1), 5.8 (test 4), 8.2 (test 3) and 9.4 (test 7) minutes. Pinch and grip endurance tests show the lowest HR strains but the highest BP ones. Figure 1 shows the evolution throughout the tests of HR and

BP.

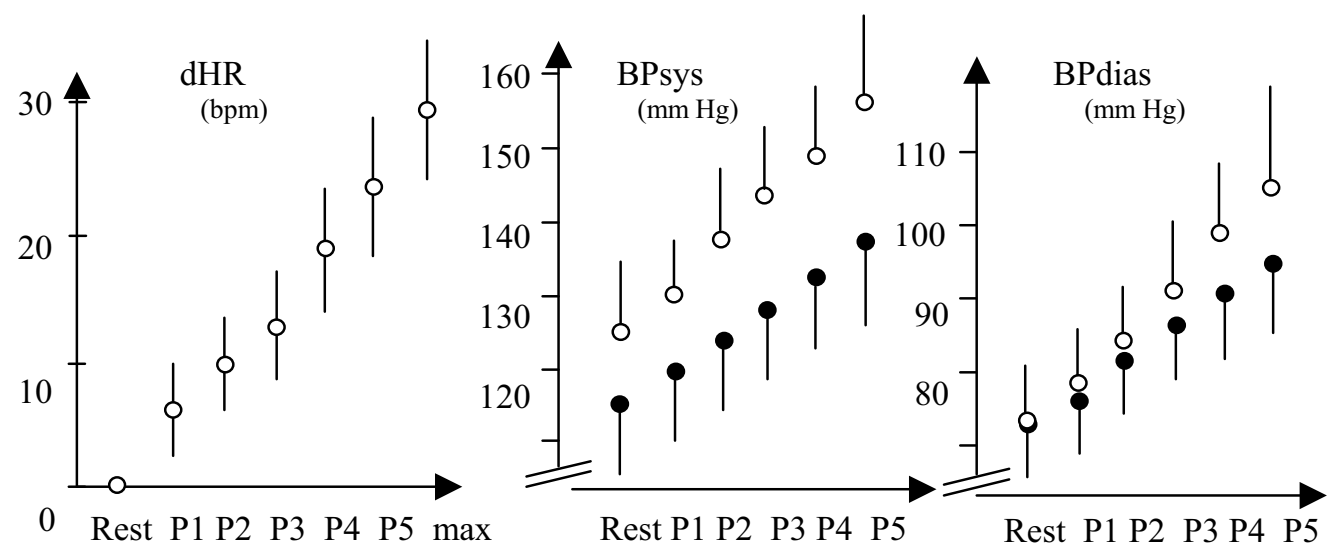

Figure 1: Mean (+/- 1 standard error) increase throughout the tests of dHR and systolic and diastolic pressure, for men (full circle) and women (circle). Results of the 7 tests are pooled and time base is split in 5 periods (Px) of the total endurance time. Rest values were recorded before the test. The value corresponding to max in the dHR diagram is recorded during the last $15 \mathrm{~s}$ of the test. 
The blood pressure increase is significantly lower for men than for women $(p<0.01)$. The final values of $\mathrm{HR}$ and BP were not very different from one test to the other. Increase in HR and systolic BP between the beginning and end of the tests were respectively for women and men $26.5(\mathrm{se}=.9)$ and $29.2(\mathrm{se}=.7)$ bpm and $24(\mathrm{se}=1.2)$ and $21(\mathrm{se}=1.0) \mathrm{mm} \mathrm{Hg}$. These mean values represent moderate heart and low blood pressure strains. However, in our study, $5 \%$ of the tests were achieved with HR increase of more than $50 \mathrm{bpm}$ and $15 \%$ with systolic BP beyond 160 $\mathrm{mm} \mathrm{Hg}$. The BP increase are related to the actual strength applied in the pinch and grip tests [3]. Whatever the test, and like cardiovascular parameters, subjective strain shows a highly significant linear increase throughout the test. Its mean value at test mid time is $6.2(\mathrm{se}=.1)$ and is not different from one test to the other.

\section{Discussion}

While mean cardiovascular strains were rather low during these experiments, this conclusion drawn from tests conducted in active young subjects must be used carefully for upper limb endurance tests applied in a general working population. Indeed, extreme strain values could occur even for tests like pinch and grip endurance. To apply functional tests to a general population, it could be proposed to record HR to be able to check at least cardiac strain. Indeed, moderate for a young active population, this one could be hazardous for middle aged unfit workers investigated in the field.

\section{References}

[1] Fallentin N. and Jorgensen K., 1992, Blood pressure response to low level static contractions. Eur. J. Appl. Physiol.,, 64, 455-459.

[2] Armstrong T.J., Chaffin D.B., Faulkner J.A., Herrin G.D. and Smith R.G., 1980, Static work elements and selected circulatory responses. Am. Ind. Hyg. Assoc. J., 41, 4, 254260.

[3] Mitchell J.H., Schybie B., Payne F.C. and Saltin B., 1981, Response of arterial blood pressure to static exercise in relation to muscle mass, force development, and electromyographic activity. Circ. Res., 48, supp 1, 6, 70-75. 